\section{International Psychogeriatrics}

Published for the International Psychogeriatric Association

\section{Editor-in-Chief}

Nicola Lautenschlager, University of Melbourne, Australia

A highly respected, multidisciplinary journal, International Psychogeriatrics publishes high quality original research papers in the field of psychogeriatrics. The journal aims to be the leading peer reviewed journal dealing with all aspects of the mental health of older people throughout the world. Circulated to over 1,000 members of the International Psychogeriatric Association, International Psychogeriatrics also features important editorials, provocative debates, literature reviews, book reviews and letters to the editor.

\section{Price information}

is available at: http://journals.cambridge.org/ipg

\section{Free email alerts}

Keep up-to-date with new material - sign up at http://journals.cambridge.org/ipg-alerts

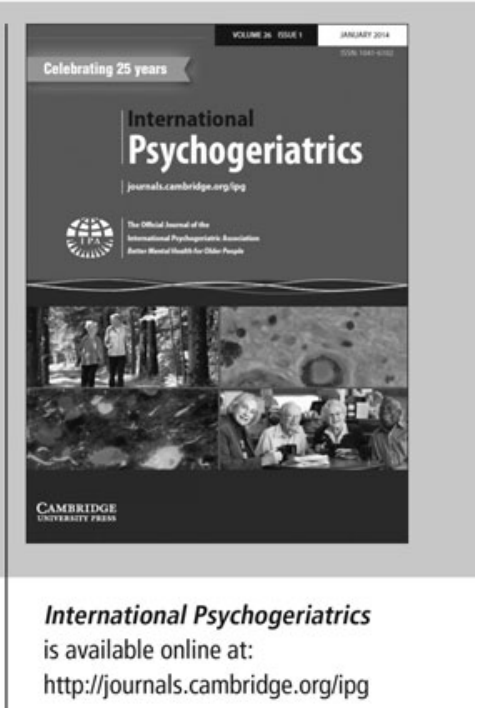

To subscribe contact Customer Services

in Cambridge:

Phone $+44(0) 1223326070$

$\mathrm{Fax}+44(0) 1223325150$

Email journals@cambridge.org

in New York:

Phone +1 (845) 3537500

$\mathrm{Fax}+1$ (845) 3534141

Email

subscriptions_newyork@cambridge.org 


\section{INSTRUCTIONS FOR CONTRIBUTORS}

\section{SUBMISSION OF MANUSCRIPTS}

Manuscripts should be submitted online via our manuscript submission and tracking site, http://www.editorialmanager.com/psm/. Full instructions for electronic submission are available directly from this site. To facilitate rapid reviewing, communications for peer review will be electronic and authors will need to supply a current e-mail address when registering to use the system.

Papers for publication from Europe (except those on genetic topics, irrespective of country), and all papers on imaging topics, should be submitted to the UK Office.

Papers from the Americas, Asia, Africa, Australasia and the Middle East (except those dealing with imaging topics), and all papers dealing with genetic topics, irrespective of country, should be sent to US Office.

Generally papers should not have text more than 4500 words in length (excluding these sections) and should not have more than a combined total of 5 tables and/or figures. Papers shorter than these limits are encouraged. For papers of unusual importance the editors may waive these requirements. A structured abstract of no more than 250 words should be given at the beginning of the article using the headings: Background; Methods; Results; Conclusions. The name of an author to whom correspondence should be sent must be indicated and a full postal address given in the footnote. Any acknowledgements should be placed at the end of the text (before the References section).

Declaration of Interest: A statement must be provided in the acknowledgements listing all financial support received for the work and, for all authors, any financial involvement (including employment, fees, share ownership) or affiliation with any organization whose financial interests may be affected by material in the manuscript, or which might potentially bias it. This applies to all papers including editorials and letters to the editor.

Contributors should also note the following:

1. S.I. units should be used throughout in text, figures and tables.

2. Authors should spell out in full any abbreviations used in their manuscripts.

3. Foreign quotations and phrases should be followed by a translation.

4. If necessary, guidelines for statistical presentation may be found in: Altman DG, Gore SM, Gardner MJ \& Pocock SJ (1983). Statistical guidelines for contributors to medical journals. British Medical Journal 286, 1489-1493.

REFERENCES (1) The Harvard (author-date) system should be used in the text and a complete list of References cited given at the end of the article. In a text citation of a work by more than two authors cite the first author's name followed by et al. (but the names of all of the authors should be given in the References section). Where several references are cited together they should be listed in rising date order. (2) The References section should be supplied in alphabetical order (authors' names in bold, journal titles in full), following the text. Some examples follow:

Miller PM, Byrne M, Hodges A, Lawrie SM, Johnstone EC (2002). Childhood behaviour, psychotic symptoms and psychosis onset in young people at high risk of schizophrenia: early findings from the Edinburgh high risk study. Psychological Medicine 32, $173-179$.

Cleckley HJ (1941). The Mask of Sanity, 2nd edn. Mosby: St. Louis, MO.

Brewer WJ, Wood SJ, DeLuca C, Pantelis C (2006). Models of olfaction for exploring neurodevelopment. In Olfaction and the Brain (ed. W. J. Brewer, D. Castle and C. Pantelis), pp. 97-121. Cambridge University Press: Cambridge.

(3) Online citations

doi (when published online prior to printed issue)

Lauritsen MB, Pedersen CB, Mortensen CB (2004). The incidence and prevalence of pervasive developmental disorders: a Danish population-based study. Psychological Medicine. Published online: 21 October 2004. doi:10.1017/ S0033291704002387.

$$
\text { URL }
$$

World Bank (2003). Quantitative techniques for health equity analysis - Technical Notes (http://siteresources.worldbank. org/INTPAH/ Resources/Publications/Quantitative-Techniques/health.eq tn07.pdf). Accessed 15 February 2006.

[Authors are requested to print-out and keep a copy of any online-only material, in case the URL changes or is no longer maintained.]

FIGURES AND TABLES Only essential figures and tables should be included. Further tables, figures, photographs and appendices, may be included with the online version on the journal website. To ensure that your figures are reproduced to the highest possible standards, Cambridge Journals recommends the following formats and resolutions for supplying electronic figures. Please ensure that your figures are saved at final publication size and are in our recommended file formats. Following these guidelines will result in high quality images being reproduced in both the print and the online versions of the journal. Line artwork: Format: tif or eps, Colour mode: black and white (also known as 1-bit), Resolution: 1200 dpi; Combination artwork (line/tone): Format: tif or eps, Colour mode: grayscale (also known as 8-bit), Resolution: 800 dpi; Black and white halftone artwork: Format: tif, Colour mode: grayscale (also known as 8-bit), Resolution: 300 dpi; Colour halftone artwork: Format: tif, Colour mode: CMYK colour, Resolution: $300 \mathrm{dpi}$. All photographs, graphs, and diagrams should be referred to as figures and should be numbered consecutively in Arabic numerals. Captions for figures should be typed double-spaced on separate sheets. Tables Tables should be numbered consecutively in the text in Arabic numerals and each typed on a separate sheet after the References section. Titles should be typed above the table.

PROOFS AND OFFPRINTS Page proofs will be sent to the author designated to receive correspondence. corrections other than to printer's errors may be charged to the author. The corresponding author of each paper will receive a PDF file of their article and hard copy offprints may be purchased if they are ordered on the form supplied when the proof is returned. 


\section{PSYCHOLOGICAL MEDICINE}

\section{CONTENTS}

\section{REVIEW ARTICLES}

Demoralization: a systematic review on its clinical characterization

Tecuta L, Tomba E, Grandi S \& Fava GA

A systematic review and meta-analysis of randomized, double-blind, placebo-controlled trials of ketamine in the rapid treatment of major depressive episodes

McGirr A, Berlim MT, Bond DJ, Fleck MP, Yatham LN \& Lam RW

Does nature have joints worth carving? A discussion of taxometrics, model-based clustering and latent variable mixture modeling

Lubke GH \& Miller PJ

\section{ORIGINAL ARTICLES}

Understanding the elevated suicide risk of female soldiers during deployments

Street AE, Gilman SE, Rosellini AJ, Stein MB, Bromet EJ, Cox KL, Colpe LJ, Fullerton CS, Gruber MJ, Heeringa SG, LewandowskiRomps L, Little RJA, Naifeh JA, Nock MK, Sampson NA, Schoenbaum M, Ursano RJ, Zaslavsky AM \& Kessler RC

Testing Ødegaard's selective migration hypothesis: a longitudinal cohort study of risk factors for non-affective psychotic disorders among prospective emigrants van der Ven E, Dalman C, Wicks S, Allebeck P, Magnusson C, van Os J \& Selten JP

Distinct neuropsychological profiles within ADHD: a latent class analysis of cognitive control, reward sensitivity and timing

van Hulst BM, de Zeeuw P \& Durston S

Revealing the dynamic network structure of the Beck Depression Inventory-II

Bringmann LF, Lemmens LHJM, Huibers MJH, Borsboom D \& Tuerlinckx $F$

Shared white-matter dysconnectivity in schizophrenia and bipolar disorder with psychosis

Kumar J, Iwabuchi S, Oowise S, Balain V, Palaniyappan L \& Liddle PF

Impulsivity in disorders of food and drug misuse

Mole TB, Irvine MA, Worbe Y, Collins P, Mitchell SP, Bolton S,

Harrison NA, Robbins TW \& Voon V
Increased visual gamma power in schizoaffective bipolar disorder

Brealy JA, Shaw A, Richardson H, Singh KD, Muthukumaraswamy SD \& Keedwell PA

White-matter relaxation time and myelin water fraction differences in young adults with autism

Deoni SCL, Zinkstok JR, Daly E, Ecker C, Consortium MRC AIMS, Williams SCR \& Murphy DGM

Blood cadmium and depressive symptoms in young adults (aged $20-39$ years)

Scinicariello F \& Buser MC

What determines continuing grey matter changes in first-episode schizophrenia and affective psychosis? Rosa PGP, Zanetti MV, Duran FLS, Santos LC, Menezes PR, Scazufca M, Murray RM, Busatto GF \& Schaufelberger MS

Gender-age interaction in incidence rates of childhood emotional disorders

Wesselhoeft R, Pedersen CB, Mortensen PB, Mors O \& Bilenberg $\mathrm{N}$

Peripheral BDNF: a candidate biomarker of healthy neural activity during learning is disrupted in schizophrenia Skilleter AJ, Weickert CS, Vercammen A, Lenroot R \& Weickert TW

Exposure to peer deviance during childhood and risk for drug abuse: a Swedish national co-relative control study Kendler KS, Ohlsson H, Mezuk B, Sundquist K, Sundquist J

Hedonic tone is associated with left supero-lateral medial forebrain bundle microstructure

Bracht T, Doidge AN, Keedwell PA \& Jones DK

Domestic and sexual violence against patients with severe mental illness

Khalifeh H, Moran P, Borschmann R, Dean K, Hart C, Hogg J, Osborn D, Johnson S \& Howard LM

Correspondence 